\title{
Teknakultura
}

Revista de Cultura Digital y Movimientos Sociales

Pantallas

\section{Basura electrónica}

Electronic trash

\section{Pedro Costa Morata}

(Universidad Politécnica de Madrid)

pcosta@euitt.upm.es

\section{Resumen}

Nacido en Amsterdam en 1959. Es autor del libro Fibra oscura, profesor de nuevos medios, cofundador de la lista de correos Nettime y un participante prolífico en la creación de una cultura crítica de la red. Este activista y conferenciante holandés combina teoría y práctica para ofrecernos una radiografía fidedigna de los nuevos medios.

\section{Palabras Clave}

Desechos, basura electrónica, Greenpeace, sostenibilidad, medio ambiente. 


\section{Abstract}

Born in Amsterdam in 1959, Lovink is the author of Dark Fiber, professor of New Media, cofounder of the mailing list NetTime and an active participant in the creation Critical Net Culture. This Dutch activist and lecturer combines theory and practice to offer a trustworthy outlook of new media

\section{Keywords}

Waste; electronic trash; Greenpeace; sustainability; environment. 


\section{Buy it, Use it, Break it, Junk it, it's Toxic http://youtu.be/4mLtheejM30}

Este video producido por la organización ecologista Greenpeace llama la atención sobre el aterrador problema presentado por la "basura electrónica", una amenaza ambiental relativamente reciente derivada del ingente consumo de aparatos electrónicos de uso individual, familiar e industrial que son sustituidos vertiginosamente por la presión comercial de los productores, y cuya gestión una vez convertidos en desechos deja mucho que desear: en una gran proporción son objeto de exportación a países que, como China e India, no se distinguen por un excesivo celo ecológico.

La electrónica, con sus derivadas la informática y las telecomunicaciones, hace tiempo que han dejado de beneficiarse de un cierto prestigio como actividades limpias -en relación, por ejemplo, con la industria energética, la minería e incluso las infraestructuras-, para acceder a un estatus de industrias o actividades sucias, tóxicas y seriamente perturbadoras del medio ambiente. En gran medida esta pérdida de gracia se debe a ese impulso fatal del consumismo, es decir, a la obsesión por sustituir los modelos por otros más modernos y capaces, que además son cada vez más baratos. Porque estamos aludiendo a una industria que basa su éxito en su carácter de productora de objetos radicalmente efímeros, diseñados y comercializados para ser perecederos, para no perdurar, es decir, para convertirse en desechos generando así un problema de proporciones gigantescas.

La "solución" que el vídeo relata es la exportación de estos desechos desde los países más consumidores y "evolucionados ambientalmente" hacia países menos escrupulosos, donde el aprovechamiento de sus componentes útiles -que es verdad que son numerosos- acaba siendo objeto de una actividad caótica, de gran impacto ecológico y sometida al caprichoso vaivén de un "mercado" informal a medias clandestino y a medias usurario. Sin embargo, esos países que se proclaman "conscientes y avanzados" en lo ambiental se sacuden su mala conciencia quitándose de encima el serio problema de la gestión de estos desechos, que al implicar un aprovechamiento minucioso y cuidadoso que demanda abundante mano de obra, no viene a interesar a ninguna industria convencional: o los gobiernos las subvencionan, o acaban siendo objeto de un tratamiento homogéneo con la basura ordinaria o, como vemos en este caso, son 
exportados al exterior sin que productores o consumidores se hagan responsables de su destino final.

Finalmente, el vídeo reconduce la puesta en evidencia del grave problema del destino de los desechos electrónicos hacia la necesidad de que las empresas responsables, sobre todo las productoras, asuman algún “código de buenas prácticas”, que es lo que parece buscar Greenpeace promoviendo su Guía destinada al efecto. La organización ecologista evita así profundizar en el enfoque crítico inicial y atacar la intencionalidad íntima de esta industria, que es el consumo masivo de productos radicalmente perecederos y efímeros; un asunto que el movimiento ecologista tradicional -al que, desde luego, no pertenece Greenpeace- siempre se ha tomado muy en serio, sin caer en la veleidad de sermonear a los culpables o brindarles alivio. En consecuencia y con ese "desenlace", Greenpeace actúa de "mentor institucional y benévolo" hacia este ciclo perverso de nuevas formas de contaminación del medio, singularmente grave en lo que atañe al recurso agua y los acuíferos. 